\title{
A Influência do Mapeamento de Processos no Desempenho da Empresa
}

\author{
The Influence of Process Mapping on Company Performance
}

\author{
Thiago Akira Nakagima ; Antonio Carlos Estender*bo \\ ${ }^{a}$ Universidade de Guarulhos. SP, Brasil. \\ bUniversidade Paulista, Programa de Pós-Graduação em Engenharia da Produção. SP, Brasil. \\ 'Faculdade de Tecnologia de Franco da Rocha. SP, Brasil. \\ *E-mail: estender@uol.com.br
}

\begin{abstract}
Resumo
O presente artigo se propõe a compreender as percepções dos stakeholders sobre processos para a aplicação prática do mapeamento de processos e visa também solucionar problemas específicos, no caso, de erros que ocorrem nos processos gerenciais e operacionais dentro da empresa, sendo estes problemas responsáveis pelos conflitos e falta de comunicação entre as partes. Tem como objetivo verificar os problemas nos setores de produção e gerenciamento dando um desempenho com mais eficiência e eficácia no ramo de oficina de carros e também identificar processos a serem corrigidos. O trabalho foi realizado por meio de estudo de caso único, em uma empresa do setor de manutenção de carros e produção de peças (oficina), onde foram realizadas 25 entrevistas de natureza qualitativa e exploratória, sendo a coleta de dados efetuada por meio de questionários destinados aos stakeholders. Observou-se que os principais resultados foram encontrados diante de entrevistas destinadas a funcionários que trabalham na empresa, verificando tudo que ocorre no presente momento e as possíveis melhorias que podem acontecer ao abordar um mapeamento de cada processo. Diante do exposto, as implicações mais relevantes foram que esta ferramenta é de suma importância para que as empresas tenham uma organização maior, separando cada processo em seu âmbito, possibilitando que consigam ter uma visão global de tudo que está situado na empresa.
\end{abstract}

Palavras-chave: Analisar. Organização. Identificar. Produtividade.

\begin{abstract}
The purpose of this article is to understand the stakeholders 'perceptions about management processes of process mapping practical application and to solve specific problems, like errors that occur during management and operational processes within the company, being these problems responsible for the conflicts and lack of communication between the parties. Our objective is to verify the problems in the production and management sectors in order to create a more efficient and effective performance in a car mechanical workshop and identify processes to be improved. The work was carried out through a case study in a company of car mechanical workshop sector, where 25 interviews of qualitative and exploratory nature were performed and the data collection was done through questionnaires intended for stakeholders. We observed that the main results found in interviews with employees who work in the company, checking how everything happens now and the possible improvements that can be done when mapping of each process. Based on this, the most relevant implications were the paramount importance of this tool for companies to achieve organization, separating each process within its scope, allowing them to get an overall view of everything that is situated in the company.
\end{abstract}

Keywords: Analyze. Organization. Identify. Productivity.

\section{Introdução}

Hunt (1996) e Biazzo (2002) vêm analisando o objeto de pesquisa, conforme apontado na revisão de literatura, em seus diferentes níveis de entendimento e aplicação ao contexto organizacional. Pode-se encontrar na literatura definições para Mapeamento de Processos, o que demanda a construção de um modelo teórico/empírico/gerencial que explicite como estes diferentes conceitos se articulam e podem contribuir para o entendimento de propostas para o desenvolvimento organizacional.

A presença do mapeamento de processos na empresa tem sido de extrema relevância para o desempenho da mesma, pois com a ausência desta ferramenta, muitas informações estão se dispersando entre os setores tornando uma produtividade muito mais complicada e demorada pelo fato de não haver o entendimento e a compreensão entre os operários. Muitas vezes um orçamento é aprovado pelo cliente, porém a gerência responsável por repassar a resposta acaba esquecendo, ou então, algumas das vezes, as empresas que frequentemente levam peças para a manutenção acabam tendo um transtorno pelo fato de o serviço ser executado sem o orçamento. Como as atividades são interdependentes, muitas vezes a falta de um setor ou o atraso dela pode ser crucial no processo produtivo em si, pois isso vai afetar de modo geral os processos da empresa. A falta desta ferramenta dentro da empresa pode acarretar em uma falta de organização nas atividades gerando conflitos entre as partes que nela se situa, concebe um mal relacionamento e mal-estar entre os colaboradores. No entanto, o artigo irá abordar como a empresa poderá encontrar uma solução para tal problema de forma que mantenha motivado 
seus funcionários e sem gerar conflitos entre as partes.

Na literatura acadêmica sobre a influência do Mapeamento de Processos no desempenho da empresa relacionada com o setor operacional existem poucos estudos sobre o objeto de pesquisa (BURGESS; SIMONS, 2005), os trabalhos identificados foram Hunt (1996) e Biazzo (2002), sendo estes os mais significativos na literatura apontada. Como o mapeamento de processos contribui para empresa ? Por que o mapeamento de processos é importante para os negócios? Quais impactos o mapeamento de processos causa nas organizações?

O objetivo do mapeamento de processos na empresa é resolver os problemas nos setores do processo produtivo e gerencial dando um desempenho com mais eficiencia e eficacia, separando cada funcionário em sua função; identificar as etapas dos processos a serem corrigidos para um atendimento ao cliente mais rápido e com maior ênfase, resultando na satisfação maior dos clientes; estabelecer meios que possibilitem tais objetivos a serem alcançados por seus funcionários pedindo opiniões diversas para que idéias de melhoria sejam colocados em prática; realizar levantamento das percepções dos stakeholders sobre o Mapeamento de Processos; elaborar ações baseadas nas percepções das situações vivenciadas pelos entrevistados para a produção de ações que possibilitem atingir os objetivos.

O presente estudo visa a contribuir para a elucidação de questões relacionadas ao objeto de pesquisa. Almeja-se preencher a lacuna empírica/gerencial identificada na relação entre mapeamento de processos.

\section{Material e Métodos}

A abordagem deste estudo é qualitativa. Maanen (1979) a define como um diferente conjunto de técnicas de interpretação com o objetivo de descrever e expressar o significado de um sistema complexo do mundo social, reduzindo distâncias entre teoria e os dados obtidos. Nessa mesma visão, Richardson (1999) justifica que esta abordagem é adequada para compreender a natureza de um fenômeno social.

Com relação aos objetivos, este estudo é de caráter exploratório, pois busca o entendimento do fenômeno na sua complexidade (GODOY, 1995). De acordo Gil, (2008), a pesquisa exploratória deve proporcionar maior familiaridade com o fenômeno ao envolver técnicas específicas, como por exemplo, a revisão de literatura. Respeitando esta abordagem e seu caráter exploratório, o estudo contempla a revisão da literatura mapeamento de processos, de acordo com Almeida (2011) e tem a finalidade de buscar relações entre conceitos, características e ideias.

Para Quivy e Campenhoudt (1998), no método de observação é importante ressaltar que este implica um alto grau de subjetividade, uma vez que as pessoas se manifestam de acordo com suas vivências, histórico de valores e aspectos culturais. Utiliza-se este tipo de pesquisa empírica quando se quer conseguir informações e conhecimento referentes a um determinado problema do qual se busca comprová-lo, ou ainda, com a intenção de descobrir novos fenômenos, percepções ou suas relações.

O estudo de caso único é dos métodos que apresenta a melhor aderência aos objetivos e às questões norteadoras do trabalho. Para Tull e Hawkins, (1976) um estudo de caso se refere a uma análise intensiva de uma situação particular. A escolha da empresa como universo de pesquisa baseou-se no relevante papel que esta desempenha na cidade de Guarulhos, SP, especialmente sua atuação na área de manutenção de automóveis. Nessa organização, foram coletadas informações referentes a Mapeamento de Processos.

A empresa auto elétrico Nippon Center se localiza na rua Dona Olinda de Albuquerque em Guarulhos - SP. A empresa teve início em 1983 tendo como proprietários Valter Lins e Marcos Miagui. Com 34 anos de existência, o negócio conta com 10 operários, 2 gerentes e 2 proprietários onde tem como proposta realizar a manutenção de automóveis e peças buscando sempre a qualidade continua em seus serviços.

Com um quadro de operários qualificados, a empresa tenta fazer o maior número possível de lucro, porém ela ainda não implantou o método de mapeamento de processos. Como cada serviço tem seu nível de dificuldade, muitas vezes algo que uma pessoa com mais experiência faz em um tempo, um funcionário que ainda não tem o mesmo nível de conhecimento faz em outro, gerando uma série de atrasos na produção e manutenção. Além disso, ainda tem os problemas de orçamentos que são aprovados ou não que são esquecidos pela gerencia e não são repassados para clientes e/ou técnicos de manutenção, acarretando em desperdício de tempo, confusão com os operários nas etapas como a desmontagem, limpeza de peças e análise para orçamento e a insatisfação dos clientes pelo fato de o serviço ainda não estar realizado, se tornando um problema processual na empresa.

Pelo fato de ser uma nova implementação de processos e uma nova forma de se executar, a empresa terá uma série de questões a se adaptar para que consiga abranger este novo método, porém a empresa conseguindo mapear estes processos, irá promover muito mais organização tanto na teoria quanto na prática. Além de corrigir atrasos na manutenção, vai gerar uma satisfação dos clientes que pode promover uma fidelidade entre cliente/empresa e a satisfação dos colaboradores que vai originar uma motivação entre eles.

Segundo Hunt (1996), o mapeamento de processos é uma ferramenta gerencial analítica e de comunicação que têm a intenção de ajudar a melhorar os processos existentes ou de implantar uma nova estrutura voltada para processos, porém pelo fato de a empresa ter um grande tempo no mercado e sempre ter trabalhado dessa forma, ela tem uma certa dificuldade para mudar ou até um certo receio, mesmo tendo em mente que é uma ferramenta que vai ser adotada para que os processos de distribuição de serviços, orçamentos, operação dos serviços 
e entrega para o cliente, sejam realizados de maneira correta e eficaz. Com essa ferramenta a empresa conseguirá muito mais rapidez e satisfação dos clientes de maneira que consiga resolver todos seus problemas de processos que ocorre entre os setores da organização. Problemas nos setores do processo produtivo e gerencial terão um desempenho com mais eficiencia e eficacia.

A utilização das entrevistas como método de coleta de dados na pesquisa qualitativa é explorar percepções, experiências, crenças e/ou motivações dos stakeholders sobre questões específicas no campo organizacional. De acordo Flick (2004) esse tipo de pesquisa busca apontar os "comos", e os "por quês" embasados nos discursos oriundos da análise das entrevistas.

Para se atingir os propósitos desse estudo buscou-se formular um roteiro de entrevistas. Os dados foram levantados e desenvolvidos a partir de material já elaborado, constituído principalmente de livro e artigos científicos, para dar o devido suporte teórico-acadêmico ao estudo (DIEHL; TATIM, 2004), é importante sublinhar que cada participante foi esclarecido sobre nossa intenção de pesquisa e decidiu participar voluntariamente. Estes constituíram um grupo considerado relevante para o alcance do objetivo da pesquisa.

Efetuou-se a pesquisa de campo com entrevistas em profundidade, com questões semiestruturadas. Foram 25 entrevistados da empresa Nippon, atuantes na cidade de Guarulhos - SP.

A análise das entrevistas foi feita de maneira empírica e interpretativa, por meio da utilização da análise de conteúdo. Os grupos operários, clientes e gerentes foram escolhidos de acordo com o critério da tipicidade (GASKELL, 2010).

A pesquisa foi realizada em duas etapas: a) análise e compreensão das pesquisas bibliográficas feitas sobre o objeto de pesquisa; b) análise e compreensão das entrevistas realizadas. Sabe-se que, desse modo, a metodologia qualitativa na pesquisa empírica, ao estabelecer relações face-a-face entre o "sujeito que pesquisa" com o "sujeito que é pesquisado", permite vínculos de reflexão entre as partes envolvidas porque estão todos em presença, isto é, frente-a-frente em diálogo.

As entrevistas para esse trabalho foram realizadas individualmente no local de trabalho, com os stakeholders de diferentes níveis hierárquicos. Alguns dos entrevistados concederam mais de um depoimento, colaborando significativamente com a pesquisa.

\section{Resultados e Discussão}

Os resultados descritos têm como base as informações colhidas nas entrevistas, mas também foram obtidas informações no site da organização que contribuíram para complementar o estudo. Os resultados visaram a responder, qual a sua opinião em relação à uma nova aplicação de processos? Por que você acha que deveria ser implantado este novo método? Você acha que este é o único ponto a ser corrigido pela empresa? As discussões apresentadas buscam traduzir a interpretação do pesquisador construídas a partir da análise das respostas obtidas, bem como, os dados obtidos a partir da observação in loco. As informações foram trabalhadas de forma a apresentar as percepções dos stakeholders com a finalidade de elaborar ações que venham contribuir para o entendimento de Mapeamento de Processos.

Quadro 1 - Percepção acerca da influência do mapeamento de processos no desempenho da empresa.

\begin{tabular}{|c|c|c|}
\hline Entrevistados & Dados Da Pesquisa & Soluções \\
\hline $\begin{array}{c}\text { Operários } \\
\text { (10) }\end{array}$ & $\begin{array}{l}\text { De acordo com o problema citado, os colaboradores concordam com a } \\
\text { implementação do mapeamento. } \\
\text { No ponto de vista deles, muitos processos são confusos e bagunçados, } \\
\text { atrapalhando tanto na produtividade quanto na compreensão. Os maiores } \\
\text { problemas estão presentes pelo fato de os setores serem interligados e faltar } \\
\text { uma comunicação e interação correta de ambas as partes. Como a empresa } \\
\text { não tem um estoque, muitas peças precisam ser pegas pelo motoboy, } \\
\text { porém muitas vezes não se é passado as informações corretas da peça e } \\
\text { consequentemente é pega a peça errada. } \\
\text { No entanto, conclui-se que a formulação e implementação deste novo } \\
\text { processo seria de total aceitação pelos funcionários, porém no ponto de vista } \\
\text { deles o problema não está apenas nesses processos, pois de acordo com } \\
\text { esses funcionários a empresa deveria ter um estoque mínimo de peças para } \\
\text { que o processo de montagem fosse mais rápido. }\end{array}$ & $\begin{array}{l}\text { Elaborar um fluxograma de todos os } \\
\text { processos, demonstrando passo a passo } \\
\text { cada atividade a ser seguida pelos } \\
\text { operários e gerência, de modo a fazer } \\
\text { com que se tenha uma produtividade } \\
\text { com menos confusões. } \\
\text { Com este fluxograma, os funcionários } \\
\text { podem realizar um trabalho com maior } \\
\text { facilidade, com maior eficiência e } \\
\text { eficácia, com mais rapidez e com } \\
\text { menos atritos. }\end{array}$ \\
\hline Clientes (13) & $\begin{array}{l}\text { Na opinião dos clientes, o mapeamento de processos é uma forma de adoção } \\
\text { que contribuiria muito para a satisfação dos mesmos, onde de fato resolveria } \\
\text { o problema da empresa. } \\
\text { A implantação deste método, fará com que a empresa tenha um maior foco } \\
\text { nos processos mais relevantes para a manutenção, gerando muito mais } \\
\text { rapidez. Muitas vezes os clientes saem insatisfeitos pelo fato de o serviço } \\
\text { ainda não estar finalizado ou o orçamento ainda não ser lhes repassado. }\end{array}$ & $\begin{array}{l}\text { Ignorar processos que causem } \\
\text { atrasos no trabalho dos operários, } \\
\text { contratar mais funcionários para que } \\
\text { não sobrecarregue os funcionários e } \\
\text { realizar treinamentos para que fiquem } \\
\text { habilitados a realizar tarefas com } \\
\text { maior rapidez e eficiência. }\end{array}$ \\
\hline Gerentes (2) & $\begin{array}{l}\text { De acordo com a opinião dos gerentes, o mapeamento de processos com } \\
\text { certeza seria uma ferramenta essencial. } \\
\text { Muito mais do que um auxílio para os processos, o mapeamento de processos } \\
\text { pode contribuir para a decisăo que eles passem a tomar. Isso ajudaria a } \\
\text { identificar os problemas mais rapidamente e solucioná-los de forma que } \\
\text { esse problema não se agrave. } \\
\text { Todavia, os gerentes vêm este novo método como um começo para a } \\
\text { correção dos problemas, pois para eles não são apenas problemas com a } \\
\text { oficina, mas também com a questão da organização de modo geral. }\end{array}$ & $\begin{array}{l}\text { Realizar investimentos em máquinas } \\
\text { e equipamentos que contribuíssem } \\
\text { para a rápida produção no setor de } \\
\text { manutenção, sistemas que contribua } \\
\text { para controle de dados, reavaliação das } \\
\text { atividades executadas pela empresa. }\end{array}$ \\
\hline
\end{tabular}

Fonte: Dados de pesquisa 
Com base nas entrevistas feita com os diretores, colaboradores e clientes, a implementação do mapeamento de processos seria ideal para resolver os problemas que se encontram na empresa, pois a implantação dela causará um grande impacto de forma positiva em relação aos processos da empresa, de modo a analisar seus erros e classifica-los de acordo com sua importância, elaborar correções nos processos de forma que não ocorra mais este tipo de causa e aplicar diante de todas as informações coletadas em suas pesquisas para que esta ação comece a ser implantada diante da organização.

Mapeamento para alavancagem dos processos: De acordo com os operários é necessário que seja elaborado um fluxograma de acordo com as atividades da empresa, sendo explicitado todos os processos para que tenha uma produtividade mais simples e eficaz, de modo que os contribua para um trabalho melhor e que se tenha uma assimilação das informações de maneira precisa, evitando interferências que causem o atraso e a falta de eficiência.

Segundo Cheung e Bal (1998), o mapeamento de processos é uma técnica que figura os processos com o intuito de analisar a melhor forma para se aplicar no negócio colocando em um diagrama dos setores. Entretanto, o autor converge de certa forma com a opinião dos operários, pois no ponto de vista dele mapear um processo é como fazer uma análise dentro da empresa e elaborar processos que sejam mais viáveis, retratando em atividades com mais simplicidade e eficácia. De acordo com o autor, o mapeamento de processos vai desenhar os processos passo a passo para que seja aplicado dentro da empresa, contribuindo de maneira que irá progredir a organização.

Segundo Oliveira (2006), o mapeamento de processos tem por finalidade detalhar as atividades através de fluxogramas. No entanto essa ferramenta traz sim uma facilidade de gerenciamento de processos, porém nem sempre a facilidade torna os processos mais simples. Muitas vezes, a aplicação correta dos processos a serem executadas pela empresa, traz uma maior facilidade de entendimento e uma simplicidade maior, todavia nem sempre se é aplicada essa questão, pois a aplicação dos processos dependerá da maneira em que a empresa realiza as suas atividades internas.

Eliminar processos desnecessários: De acordo com os clientes, a solução é analisar quais as etapas não estão sendo importantes para os processos da empresa e assim removêlos para que haja uma maior rapidez e objetividade em seu trabalho, de maneira que todos os problemas processuais sejam corrigidos. Na visão desses entrevistados, muitos processos que são de maior burocracia entre os funcionários e a empresa, poderiam ser reavaliados para que houvesse alteração na execução dessas atividades.

Segundo Soliman (1999), o mapeamento de processos é utilizado para projetar etapas dos processos dando foco nas atividades relevantes para o negócio. Entretanto, é possivel identificar que o autor converge a hipótese dos clientes pelo fato de o mapeamento de processos ser uma ferramenta que auxilia na identificação de todas as atividades que são realizadas, separando por processos de maior e menor importância. Tais atividades vão ser avaliadas e implementadas, dependendo de sua classificação de importância dentro da organização.

Para Rother e Shook (2000), mapear processos é ter visão como um todo, analisando tanto as atividades mais relevantes quanto os de menos valor. Entretanto, nota-se que o autor analisa esta ferramenta de outro modo, pois o mapeamento não vai remover os processos de menor relevância, mas sim analisar e absorver todas informações para que este processo seja complementado e incrementado, tornando um processo que não pode ser simplesmente excluido.

Investimento em novas máquinas e sistemas para controle: De acordo com os gerentes, a empresa precisa da adoção do mapeamento para uma melhor eficácia no trabalho e melhor desempenho de seus funcionários em relação ao seu trabalho, mas precisa também de novos investimentos em sistemas para controle de dados, auxilio em decisões e máquinas para maior produtividade de seus operários para que tal aplicação seja realmente exercida.

Para Johansson (1995), o mapeamento dos processos pode ser conhecido como modelagem de dados, onde se melhorou da necessidade de controla-los. Entretanto, é possivel identificar que o autor converge a opinião dos gerentes, pois além da organização que o mapeamento de processos fornece entre os setores, também contribui para que se tenha o controle de dados nos quais os gerentes conseguem analisar melhor as situações que ocorrem na empresa e implementar possiveis soluções em relação aos problemas decorrentes da empresa.

Segundos Datz (2004), mapeamento de processos é uma ferramenta que analisa estratégias para melhorar o desempenho do negócio e auxilia nas decisões. Todavia, o mapeamento de processos é uma ferramenta que "auxilia" as empresas nas tomadas de decisão, entretanto não vai ser tal método que vai tornar a decisão correta, mas a empresa que irá analisar as possiveis questões a serem aplicadas e escolher a melhor forma de se sobrepor tais estratégias.

É necessario a criação de um novo sistema software que auxilie no armazenamento de dados empresariais no qual todos os setores tenham acesso, tornando os processos da empresa mais agil e prático. Com a adoção deste sistema, os processos se torão mais claros e simples e as informações de maior compreensão por parte dos operários dando maior ênfase a produtividade e manutenção. Além deste sistema, a empresa passará a ter um estoque mínimo de peças para que a produtividade seja mais prática e de maior rapidez, oferecendo maior dinâmica nas atividades da empresa. Para Fleury e Oliveira (2001), o processo de formação de redes nas empresas e suas funções tem um tipo de competência e conhecimento por elas dominados. Assim, para participar da cadeia de fornecimento de informações, cada empresa deve adotar a estratégia e desenvolver as competências necessárias, para inovação e operações a fim de garantir a eficiência coletiva. 
Deve ser eliminado os padrões da empresa de se fazer ordem de serviço em folhas de papéis e passar a se fazer através de software para uma maior eficiência e segurança na armazenagem destes dados, diminuindo o risco de se perder e criar um possível atrito entre o ambiente interno (funcionários) e ambiente externo (clientes). Com o sistema, a armazenagem de orçamentos e relações de peças podem ser feitas via internet, facilitando o processo de pedido de peça caso não haja e a comunicação para se repassar o orçamento para os clientes. Além das ordens de serviços, deve ser eliminado também a armazenagem de peças danificadas ou com defeito que possam intervir na produtividade do operário, pois muitas vezes pode-se interferir na locomoção e na montagem das peças. Para Teltech (1998), a chave para a boa escolha consiste na busca de um software que se adapte facilmente às necessidades específicas da comunidade de usuário final e que atenda aos requisitos técnicos do ambiente informacional já existente na empresa.

Deve ser diminuído a dependência de a empresa precisar de um motoboy para que busque as peças necessárias para os operários, pois muitas vezes se acaba ocorrendo atraso por parte do motoboy e o processo de montagem se atrasa, gerando insatisfação aos clientes. Muitas vezes também, os equipamentos acabarem quebrando e os operários precisam para o serviço para fazer a manutenção, entretanto essa ocorrência deve ser diminuída contratando serviços de terceiros para a manutenção. Também deve diminuir a sobrecarga de informações para o encarregado, dividindo tais informações com todos os funcionários para que não se dependa totalmente de uma pessoa. Conforme Aquino (1980) é perceptível que as novas exigências do mundo competitivo acabem por pressionar as organizações a alcançar um novo patamar em seu processo produtivo, contudo, elas precisam desenvolver a capacidade de se modificarem, de se adaptarem e oferecerem caminhos criativos e surpreendentes de flexibilidade e sabedoria. Com isso terão meios para superar os desafios e obter contínuo aprendizado.

Deve ser elevado o investimento em sistemas tecnológicos, como softwares para facilitar o armazenamento de dados, em máquinas e equipamentos para uma produtividade mais eficiente por parte dos operários, investir em funcionários que sejam especificamente para o estoque pelo fato de a empresa adotar a opção de se ter um estoque mínimo e também o aprofundamento da empresa em fluxogramas de processos que facilitem tanto os operários com a gerência na análise de atividades internas. Como afirma Castells (1999), computadores, sistemas de comunicação, decodificação e programação genética são todos amplificadores e extensões da mente humana. Para ele, os usuários apropriam-se da tecnologia e a redefinem, e assim as novas tecnologias de informação não são simplesmente ferramentas a serem aplicadas, mas processos a serem desenvolvidos.

Entretanto, conclui-se que com o mapeamento de processos, os problemas nos setores do processo produtivo e gerencial são corrigidos e empenhadas de maneira correta, respondendo tais perguntas como: Como o mapeamento de processos contribui para empresa? Por que o mapeamento de processos é importante para os negócios? Quais impactos o mapeamento de processos causa nas organizações?. Com tal ferramenta, o administrador passa a ter uma visão global de tudo que está se passando no interior da empresa e também no ambiente externo com seus concorrentes, dando um enfoque em seus objetivos de maneira que possa contribuir de maneira positiva em seus processos se tornando uma ferramenta significativa para o sucesso do negócio, pois faz com que a organização se posicione de maneira correta em relação aos seus concorrentes, impactando positivamente nos processos da empresa.

Com isso, o gestor passa a ter uma visão global de tudo que está se passando no interior da empresa e também no ambiente externo com seus concorrentes, dando um enfoque em seus objetivos de maneira que possa auxiliar em seus processos. Segundo Hunt (1996), o mapeamento foi desenvolvido para uma melhoria no desempenho, utilizado como uma ferramenta de apoio para os processos do negócio; mas também, utilizada para auxiliar nos processos decisórios e na identificação das necessidades de cada processo, pois muitas vezes as pessoas não conseguem identificar problemas que ocorrem na empresa pelo fato de estarem olhando as atividades de forma única.

O mapeamento é significativo na empresa pelo fato de ser uma ferramenta onde analisa todos os fatores que estão decadentes e precisam ser melhoradas e complementadas para que tal processo, seja nos conformes da empresa. Segundo Villela (2000), o mapeamento de processos é um método que analisa meios que contribuam para a melhoria dos processos; como também auxilia o negócio em sua gestão dando mais facilidade aos gestores para que tomem as decisões corretas, gerando uma maior ênfase nos objetivos que foram traçados.

Através deste mapeamento, a empresa terá todos os seus processos que implicam diretamente de maneira correta, impactando para que todas as ações realizadas siga nos conformes de maneira que facilite o processo dos operários gerando uma satisfação internamente com os funcionários e externamente com seus clientes. Segundo Harrington, (1991), mapeamento de processos retrata por meio de diagrama os processos existentes ou inovadores, constatando as atividades de relevancia; pois com o mapeamento de processos, a empresa vai identificar quais são as atividades de menor relevância e vai contornar a situação de forma a não deixar de lado tais atividades e ao mesmo tempo corrigindo todas suas defasagens.

Entretanto o plano de ação a ser captado pela empresa, será de elaborar um fluxograma onde evidencie passo a passo tudo que os funcionários precisarão realizar ou eliminar para que os processos fiquem mais rápidos e objetivos. Através disso, 
descomplicará o fluxo de elementos e informações, realizando um fluxograma funcional do interior da empresa onde mostrará todas as funções e atividades que deverão ser executados pelas pessoas para que se torne algo sucessivo, evitando retrabalhos por conta dos operários, etapas desnecessárias e redundâncias.

\section{Conclusão}

Os principais resultados demonstraram que objetivos propostos foram alcançados, pois com a integração desta do mapeamento de processos, os problemas que estavam ocorrendo, como por exemplo, a falta de interação dos setores de maneira correta, informações repassadas de maneira correta, falta de um sistema integrado, entre outros, foi corrigida. A produtividade e manutenção das peças estão sendo realizadas de maneira mais ágil e eficiente, pelo fato de se ter adotado novos processos corretivos em relação a maneira como se trabalhava, trazendo valores para a empresa e a satisfação dos clientes. Tais resultados foram alcançados pelo fato de a empresa aderir uma mudança em seus processos gerenciais e operacionais, adotando novos sistemas para o armazenamento de dados de clientes, informações sobre orçamento, novos processos a serem aplicados na parte operacional e a decisão de se obter um estoque para que os processos sejam realizadas de maneira mais rápida.

A princípio, tinha-se receio de que o questionamento sobre os temas desta pesquisa não fosse bem compreendido pelos stakeholders durante a entrevista, porém foi surpreendente o entendimento deles quanto aos assuntos tratados, acreditandose que isso se deve pela própria rede de informações que faz parte de seu cotidiano.

Diante do exposto as implicações mais relevantes são de natureza empírico/gerencial, pois durante a realização da pesquisa constatou-se a necessidade de melhorar os processos e a forma como serão aplicados de forma a garantir o entendimento entre a parte interna da empresa e a satisfação dos clientes, que são eixos empíricos e gerenciais mais condizentes com as necessidades expressas da organização no atual contexto da empresa. De acordo com o estudo realizado, vemos que o mapeamento de processos é de suma importância nas empresas, pelo fato de adequar todos os seus processos operacionais e gerenciais, de modo a criar uma excelência em seus métodos.

Como sugestão de estudos futuros, é necessário ampliar a amostra para outras revisões de literatura, ampliar o período de tempo para possibilitar uma visão mais abrangente do emprego dos métodos de pesquisa, podendo apresentar contribuições significativas como, por exemplo, permitir novas contribuições metodológicas na área e ampliar a análise dos resultados e, por fim, a realização de futuras pesquisas ligando o objeto de pesquisa da influência do mapeamento de processos no desempenho da empresa com as escolhas metodológicas que se demostrariam relevantes no sentido de verificar tendências e oportunidades de pesquisa, para que os profissionais e gestores da área tenham mais clareza sobre o tema.

\section{Referências}

AQUINO, C.P. Administração de recursos humanos: uma introdução. São Paulo: Atlas, 1980.

ALMEIDA, M.S. Elaboração de projeto, TCC, dissertação e tese: uma abordagem simples, prática e objetiva. São Paulo: Atlas, 2011.

BARNES, R.M. Estudo de movimentos e de tempos. São Paulo: Edgard Blücher, 1982.

BIAZZO, S. Process mapping techniques and organisational analysis: lessons from sociotechinical system theory. Business Proc. Manag. J., v.8, n.1, p.42-52, 2002.

BURGESS, P.W.; SIMONS, J.S. Theories of frontal lobe executive function: clinical applications. In: HALLIGAN, P.W.; WADE, D.T. Effectiveness of rehabilitation for cognitive deficits. Oxford: Oxford University, 2005.

CASTELLS, M. A sociedade em rede. São Paulo: Paz e Terra, 1999.

CHEUNG, Y.; BAL, J. Process analysis techniques and tools for business improvements. Business Proc. Manag. J. , v.4, n.4, p.274-290, 1998.

CORREA H.L.; CORREA, C.A. Administração de produção $e$ operações. São Paulo: Atlas, 2006.

DATZ, D.; MELO, A. C. S.; FERNANDES, E . Mapeamento de processos como instrumento de apoio à implementação do custeio baseado em atividades nas organizações. In: ENCONTRO NACIONAL DE ENGENHARIA DE PRODUÇÃO, 2004, Florianópolis. 2004.

DIEHL, A. et al. Pesquisa em ciências sociais aplicadas; métodos e técnicas. São Paulo: Pearson Prentice Hall, 2004.

FLEURY, M.T.L; FLEURY, A. Construindo o conceito de competência. RAC, v.5, n.spe, p.183-196, 2001. doi: http:// dx.doi.org/10.1590/S1415-65552001000500010.

FLEURY, M.T.L.; OLIVEIRA, M.MJ. Gestão estratégica do conhecimento: integrando aprendizagem, conhecimento e competência. São Paulo: Atlas, 2001.

FLICK, U. Uma introdução à pesquisa qualitativa. São Paulo: Bookman, 2004.

GASKELL, G. Entrevistas individuais e grupais. In: BAUER, M.W.; GASKELL, G. Pesquisa qualitativa com texto, imagem e som: um manual prático. Petrópolis: Vozes, 2010. p.64-89.

GIL, A.C. Como elaborar projetos de pesquisa. São Paulo: Atlas, 2008.

GODOY, A.S. Introdução à pesquisa qualitativa e suas possibilidades. Rev. Adm. Emp., v.35, n.2, p.57-63, 1995.

HARRINGTON, H.J. Business process improvement: the breakthrough strategy for total quality, productivity and competitiveness. New York: McGraw Hill, 1991.

HUNT, V.D. Process mapping: how to reengeneer your business processes. New York: John Wiley \& Sons, 1996.

JOHANSSON, H.J. et al. Processos de negócios. São Paulo: Pioneira, 1995.

JOHNSTON, R.; CLARK, G. Administração de operações de serviços. São Paulo: São Paulo, 2002.

KETTINGER, W.; TENG, J.T.C.; GUHA, S. Business process change: a study of methodologies, techniques, and tools. MIS 
Quarterly, v.21, n. 1, p.55-80, 1997.

MAANEN, J.V. Reclaiming Qualitative methods for organizational research: a preface, in administrative. Sci. Quarterly, v.24, n. 4, 1979.

MELLO, A.E.N. Aplicação do mapeamento de processos e da simulação no desenvolvimento de projetos de processos. Itajubá: Universidade Federal de Itajubá, 2008.

OLIVEIRA, D.P.R. Sistemas, organização e métodos: uma abordagem gerencial. São Paulo: Atlas, 2006.

QUIVY, R.; CAMPENHOUDT, L. Manual de investigação em Ciências Sociais. Lisboa: Gradiva, 1998.

RICHARDSON, R.J. Pesquisa social: métodos e técnicas. São Paulo: Atlas, 1999.

ROTHER, M.; SHOOK, J. Learning to see. USA: The Lean Enterprise Institute, 2000.

ROTONDARO, R.G. et al. Gerenciamento por Processos. In: CARVALHO, M.M. et al. Gestão da qualidade: teoria e casos. Rio de Janeiro: Elsevier, 2005
SHOSTACK, G.L. Designing services that deliver. Harvard Business Review, 1984.

SLACK, N.; CHAMBERS, S.; JOHNSTON, R. Administração da produção. São Paulo: Atlas, 2009.

SOLIMAN, F. Optimum level of process mapping and least cost business process re-engineering. Int. J. Oper. Production Manag., v.18, n.9/10, 1999.

TELTECH. A Comparison of Major Knowledge Retrieval and Management Software. Online. Minneapolis: Teltech Corporation, 1998.

TSENG, M.M.; QINHAI, M.; SU, C.J. Mapping customers service experience for operations improvement. Business Proc. Manag. J., v.5, n.1, p.50-64, 1999.

TULL, D.S.; HAWKINS, D.I. Marketing research, meaning, measurement and method. London: Macmillan Publishing, 1976.

VILLELA, C.S.S. Mapeamento de processos como ferramenta de reestruturação e aprendizado. Florianópolis: Universidade Federal de Santa Catarina, 2000. 